Tohoku J. Exp. Med., 2016, 239, 243-249

Review

\title{
Therapeutic Benefits of Laughter in Mental Health: A Theoretical Review
}

\author{
JongEun Yim ${ }^{1}$ \\ ${ }^{1}$ Department of Physical Therapy, Sahmyook University, Seoul, Republic of Korea
}

\begin{abstract}
In modern society, fierce competition and socioeconomic interaction stress the quality of life, causing a negative influence on a person's mental health. Laughter is a positive sensation, and seems to be a useful and healthy way to overcome stress. Laughter therapy is a kind of cognitive-behavioral therapies that could make physical, psychological, and social relationships healthy, ultimately improving the quality of life. Laughter therapy, as a non-pharmacological, alternative treatment, has a positive effect on the mental health and the immune system. In addition, laughter therapy does not require specialized preparations, such as suitable facilities and equipment, and it is easily accessible and acceptable. For these reasons, the medical community has taken notice and attempted to include laughter therapy to more traditional therapies. Decreasing stress-making hormones found in the blood, laughter can mitigate the effects of stress. Laughter decreases serum levels of cortisol, epinephrine, growth hormone, and 3,4-dihydrophenylacetic acid (a major dopamine catabolite), indicating a reversal of the stress response. Depression is a disease, where neurotransmitters in the brain, such as norepinephrine, dopamine, and serotonin, are reduced, and there is something wrong in the mood control circuit of the brain. Laughter can alter dopamine and serotonin activity. Furthermore, endorphins secreted by laughter can help when people are uncomfortable or in a depressed mood. Laughter therapy is a noninvasive and non-pharmacological alternative treatment for stress and depression, representative cases that have a negative influence on mental health. In conclusion, laughter therapy is effective and scientifically supported as a single or adjuvant therapy.
\end{abstract}

Keywords: alternative treatment; depression; laughter; mental health; stress

Tohoku J. Exp. Med., 2016 July, 239 (3), 243-249. 두 2016 Tohoku University Medical Press

\section{Introduction}

Recently, there has been increased interest in noninvasive and non-pharmacological therapy. Laughter therapy in the media has grown and many researchers have conducted a variety of studies on laughter (Cho and Oh 2011). Moreover, as laughter therapy does not require specialized preparations such as suitable facilities and equipment, is not prohibited by cost, does not depend on when or where it happens, and is easily accessible and acceptable, the medical world has also introduced it into treatment programs (Mora-Ripoll 2010; Ko and Youn 2011). Laughter therapy physiologically reduces the level of stress hormones, increases the level of health promoting-hormones such as endorphins, and strengthens the immune system by increasing the number of T-lymphocytes through activation of natural killer cells, which multiplies white blood cells in the body, and Ig A, G, and M, which raises immunity in the body (Bennett and Lengacher 2006; Hayashi et al. 2007; Bennett and Lengacher 2009). In addition, it also has an effect of reducing blood pressure by controlling vasoconstriction by lowering the degradation of the vasorelaxant substance, nitric oxide, and reducing cortisol thus raising blood sugar (Bennett and Lengacher 2008; Hasan and Hasan 2009). As for the mental effects of the laughter therapy, it helps reduce unpleasant feelings such as tension, anxiety, hatred, and anger, alleviates stress and depression, aids better interpersonal relationships, and improves insomnia, memory failure, and dementia (Takeda et al. 2010; Ko and Youn 2011; Bains et al. 2015).

In modern society, high levels of stress are caused by fierce competition and socioeconomic stressors. As this stress has a negative impact on self-esteem, which affects quality of life and personal motivation, it increases depression and leads to a harmful influence on a person's mental health. Furthermore, a potential mental health problem may lead to the affected person having many difficulties in maintaining a good lifestyle at home and work life (Bast and Berry 2014). Moreover, there are many problems related to the elderly in society due to the nature of an aging

Received April 7, 2016; revised and accepted June 27, 2016. Published online July 16, 2016; doi: 10.1620/tjem.239.243.

Correspondence: JongEun Yim, DSc., Department of Physical Therapy, Sahmyook University, Hwarangro 815, Nowon-gu, Seoul 139-

742, Republic of Korea.

e-mail: jeyim@syu.ac.kr 
society. In particular, problems regarding the mental health of elderly people are being magnified. Depression, secondary to loneliness and physical discomfort due to aging, is a most important emotional problem in old age and requires social attention and positive intervention. In addition to depression, another remarkable change in the mental function of the elderly is the loss of intellectual ability (Takeda et al. 2010; Ko and Youn 2011). This disorder of cognitive function can put a high burden on a person, their family, and society as a whole. The patient, and their family, can suffer from physical and psychological stress. Laughter, as part of the solution to these mental health problems, might provide a desirable noninvasive and non-pharmacological therapy that restores their happiness, by making the human body and soul healthy, and improving quality of life and self-esteem.

\section{Theory}

\section{Laughter}

Laughter is a physical reaction seen in humans and some other species of primates, consisting typically of rhythmic, often audible, contractions of the diaphragm and other parts of the respiratory system. It is a response to certain external or internal stimuli. Laughter can arise from activities such as being tickled, or from humorous stories or thoughts (Stearns 1972; Schultz and Horibe 1974). Most commonly, it is considered the expression of a number of positive emotional states, such as joy, mirth, happiness, relief, etc. On some occasions, however, it may be caused by contrary emotional states such as embarrassment, apology, or confusion, for example, nervous laughter. Age, gender, education, language, and culture are all factors as to whether a person will experience laughter in a given situation (Omwake 1937).

Dr. Miletus in the $4^{\text {th }}$ century said, Laughter is gelos in Greek, and the root of this word is Hele, which means Health.; philosophers in the $16^{\text {th }}$ century, Laughing is also like taking physical exercise.; Kant in the $18^{\text {th }}$ century, Laughter has a great influence on keeping balance in physical health.; Spencer in the $19^{\text {th }}$ century, Laughter helps ease tension and recover health (Dean and Gregory 2004; Hyeong Woo 2010). The word, laughter, comes from 'hliehhan' in Old English. The word imitated sounds of laughter. Laughter might be represented by the regular continuation of syllables made with short vowels such as "haha", "ho-ho", and "he-he" in English. Laughter is also a general feature of people that occurs instinctively when socially talking to each other (Provine 2000). Laughter is the expression of one's joyful heart or feeling when their desire is satisfied; it can be a spontaneous expression of their emotion when they have a joyful feeling or heart, physical stimulus or pleasure, or a heart or feeling physically arousing when they feel ridiculous of an odd word, behavior or appearance. It can also be a phenomenon of expressing a heart or feeling that shows one's pleasant mental activities; it physically shows the working of one's own mind and the state of their consciousness.' Laughter is laughing pleasantly, briskly, and loudly, and it is a natural phenomenon that happens in reaction to one's senses or heart, or to a word or behavior that makes another laugh (Bennett and Lengacher 2006).

\section{Laughter Theories}

There are three categories in the theories of laughter: arousal, discrepancy, and superiority (Apte 1985; Lefcourt and Martin 2012). First, the arousal theory is concerned with the cognitive aspects of laughter; stress increases arousal, while laughter is able to reduce stress by easing arousal and tension. This theory says if people laugh in a stressful situation their physical arousal state declines and the stressful situation is no longer as negative or detestable. That is to say, the theory suggests that laughter shows a complicated interaction of mind and body between cognition and emotion, rooted in the brain and nervous system. Freud (1928) also considered laughter as a mechanism that can block the attacks of another, and stated that it reduces negative emotional responses or unpleasant feelings (Freud 1928). Second, discrepancy theory is concerned with the cognitive aspect, which says laughter starts from the dithered process, situation, or thought apart from the knowledge or logic that people commonly know. This theory says people laugh when they realize there is discrepancy between the actual situation and their general knowledge of it. The theory has a viewpoint emphasizing logical, linguistic, and cognitive aspects. Laughter happens at the moment misunderstanding and bewilderment arouse in communication, deviating from the smooth course of the cognitive process. Laughter occurs at the moment cognitive imbalance - that is, the point of discrepancy or disharmony - disappears and balance recovers. Laughter at this moment is an expression of pleasant enlightenment. According to the discrepancy theory, people can laugh not only when they meet something different from their expectation but also when they meet something in discord with their expectation (Keith-Spiegel 1972). Third, the superiority theory says that laughter occurs when people look down on others more than who they are actually, or when they have a feeling or thought that they are superior to others. The theory says laughter restricts the external environment and raises confidence (MacGhee and Pistolesi 1979). By raising contentment without going against the grain, laughter allows people to take adequate action against stress and increases confidence (Martin 2010).

\section{Categories of Laughter}

Five large categories can be summarized from a medical and therapeutic point of view: (1) genuine or spontaneous laughter; (2) simulated laughter; (3) stimulated laughter; (4) induced laughter; and (5) pathological laughter (Table 1). Spontaneous laughter, unrelated to one's own free will, is triggered by different (external) stimuli and positive emotions. It has been reported that spontaneous 
Table 1. Main characteristics of five large categories of laughter.

\begin{tabular}{|c|c|}
\hline Categories & Characteristics \\
\hline Spontaneous laughter & $\begin{array}{l}\text { Unrelated to one's own free will, is triggered by different (external) stimuli and } \\
\text { positive emotions. }\end{array}$ \\
\hline Simulated laughter & $\begin{array}{l}\text { Is triggered by oneself at will (self-induced), with no specific reason (purposeful, } \\
\text { unconditional), and therefore not elicited by humor, fun, other stimuli, or positive } \\
\text { emotions. }\end{array}$ \\
\hline Stimulated laughter & $\begin{array}{l}\text { Happens as a result of the physical contact or action (reflex) of certain external } \\
\text { factors (i.e. to be ticklish, specific facial or bodily motions, by pressing laughter } \\
\text { bones). }\end{array}$ \\
\hline Induced laughter & $\begin{array}{l}\text { Is a result of the effects of specific drugs or substances (i.e. alcohol, caffeine, } \\
\text { amphetamines, cannabis, lysergic acid diethylamide or LSD, nitrous oxide or } \\
\text { "laughing gas", and more). }\end{array}$ \\
\hline Pathological laughter & $\begin{array}{l}\text { Is secondary to injuries to the central nervous system caused by various temporary } \\
\text { or permanent neurological diseases and may also occur with certain psychiatric } \\
\text { disorders. }\end{array}$ \\
\hline
\end{tabular}

Table 2. Physiological and psychological effects of laughter.

\begin{tabular}{|c|c|}
\hline Physiological outcomes & Psychological outcomes \\
\hline $\begin{array}{ll}\text { - } & \text { Exercises and relaxes muscles } \\
\text { - } & \text { Improves respiration } \\
\text { - } & \text { Stimulates circulation } \\
\text { - } & \text { Decreases stress hormones } \\
\text { - } & \text { Increases the immune system's defenses } \\
\text { - } & \text { Elevates pain threshold and tolerance } \\
\text { - } & \text { Enhances mental functioning }\end{array}$ & $\begin{array}{l}\text { - Reduces stress, anxiety, and tension, and } \\
\text { counteracts symptoms of depression } \\
\text { - Elevates mood, self-esteem, hope, energy, } \\
\text { and vigor } \\
\text { - } \quad \text { Enhances memory and creative thinking } \\
\text { - Improves interpersonal interaction } \\
\text { - Increases friendliness and helpfulness } \\
\text { - } \quad \text { Promotes psychological well-being } \\
\text { - Improves quality of life and patient care } \\
\text { - Intensifies mirth and is contagious }\end{array}$ \\
\hline
\end{tabular}

laughter causes typical contractions of the muscles around the eye socket (Ekman et al. 1990). Simulated laughter is triggered by oneself at will (self-induced), with no specific reason (purposeful, unconditional), and therefore not elicited by humor, fun, other stimuli, or positive emotions. Stimulated laughter happens as a result of the physical contact or action (reflex) of certain external factors (i.e. to be ticklish, specific facial or bodily motions, by pressing laughter bones) (García-Rodera 2007). Induced laughter is a result of the effects of specific drugs or substances (i.e. alcohol, caffeine, amphetamines, cannabis, lysergic acid diethylamide or LSD, nitrous oxide or "laughing gas", and more). Lastly, Pathological laughter is secondary to injuries to the central nervous system caused by various temporary or permanent neurological diseases and may also occur with certain psychiatric disorders. Pathological laughter is developed with no specific stimulus, is not connected with emotional changes, has no voluntary control of its duration, intensity or facial expression, and sometimes comes with "pathological crying" (Wortzel et al. 2008).

\section{Physiological and Psychological Effects of Laughter}

Laughter has numerous effects involving the muscular, cardiovascular, respiratory, endocrine, immune, and central nervous systems (Table 2). The effects of laughter on certain physiological outcomes are as follows: laughter (1) exercises and relaxes muscles, (2) improves respiration, (3) stimulates circulation, (4) decreases stress hormones, (5) increases the immune system's defenses, (6) elevates pain threshold and tolerance, and (7) enhances mental function- 
ing (Martin and Lefcourt 2004; Sahakian and Frishman 2007; Ripoll and Rodera 2008).

The psychological effects of laughter relate primarily to both its use as a coping mechanism and, to a lesser extent, its enhancement of interpersonal relationships. The research reviewed in this area, greater in volume and strength than the evidence for physiological health benefits, can be summarized as follows: laughter (1) reduces stress, anxiety, and tension, and counteracts symptoms of depression; (2) elevates mood, self-esteem, hope, energy, and vigor; (3) enhances memory, creative thinking, and problem solving; (4) improves interpersonal interaction, relationships, attraction, and closeness; (5) increases friendliness and helpfulness and builds group identity, solidarity, and cohesiveness; (6) promotes psychological well-being; (7) improves quality of life and patient care; and (8) intensifies mirth and is contagious (Scholl and Ragan 2003; Gelkopf et al. 2006; Arminen and Halonen 2007).

\section{Laughter Therapy}

Laughter therapy is a kind of communication that arouses laughter, smiling, pleasant feelings, and enables interaction. Laughter therapy uses laughter for the purpose of treatment to promote leading a desirable life, by keeping, recovering, and preventing physical, psychological, social, mental and spiritual functions through spontaneous and nonspontaneous laughter (Mora-Ripoll 2010). This is a different approach from general medical treatments; it focuses on the approach that both body and mind can be healthy only when the psychological aspects of the brain are changed, beyond just physical treatment. According to the American Association for Therapeutic Humor (AATH), laughter therapy refers to an activity that improves a patient's health and welfare using interesting experiences and expressions. Therefore, laughter therapy can be a series of cognitive-behavioral therapies that helps make physical, psychological, and social relationships healthy and ultimately improves the quality of life (Ko and Youn 2011). It has taken a very long time for laughter to become a recognized medical therapy. Although it started with Hippocrates and Aristotle, laughter therapy was not again acknowledged until the $20^{\text {th }}$ century. Norman Cousins in the mid- $20^{\text {th }}$ century established the effects of laughter in a modern setting and brought the naissance of laughter therapy. He was the editor-in-chief of the 'Saturday Review' of America. Cousins suffered from ankylosing spondylitis, and realized at the age of 50 that he did not feel pain for 2 hours when he laughed while watching TV comedy programs. Discovering this fact, he was invited by the California University Hospital and began to earnestly study the medical effects of laughter and acknowledged the clinical effects of laughter. In his book, 'Anatomy of an Illness', Cousins stated 'laughter is like a bulletproof vest', and wrote about the apparently remarkable power of affirmation and laughter therapy. He later went on to become a professor and studied the effectiveness of laughter on health, and is often referred to as the father of laughter therapy (Cousins 1989). Since then, theses reporting that laughter helps relieve stress and helps cure illness began to be released and laughter therapy spread in North America. Over the course of 40 years of study, Dr. William Fry of Stanford University School of Medicine developed a theory of laughter therapy, and found that humor and laughter produced natural painkillers in pituitary, such as endorphins, improved blood circulation, and decreased stress (Fry and Salameh 1987). In addition, in 1996 Prof. Lee Berk of Loma Linda University School of Medicine in California, found that 'laughter increases immune globulin 3 times and interferon 200 times'; he found after 18 years of study that natural killer cells were activated by laughter (Berk et al. 1989b; Berk and Tan 1995).

\section{Laughter and Stress}

Stress became an official term when the Canadian doctor, Hansselye, first presented a theory of general adaptation syndrome, based on the results of various kinds of animal testing (Evans 1982). The root of the word stress is from 'stringer' in Latin, which means 'tighten'. In the $17^{\text {th }}$ century, it was used to describe pressure or physical tension; in the $20^{\text {th }}$ century, stress evolved to mean the psychological pressure and tension that people receive from the outside (Ivancevich and Matteson 1980; Sonnentag and Frese 2003).

Lazarus and Folkman (1984) considered stress as the specific relation between an individual and the environment when people think that a personal resource is lacking and their comfort is at risk (Lazarus and Folkman 1984). Stress can be classified into three kinds: stress as a stimulus, as a response, and as an interaction. First, stress as a response is interested in the psychological and physiological response to surroundings; it considers stress a certain response to the break or change in physiological, physical, behavioral, and emotional equilibrium or the response trying to maintain homeostasis in the face of various stimuli. Second, stress as a stimulus is to receive a stimulus from a special image or form; it includes various stimuli from the surroundings such as the external environmental conditions and internal physiological phenomena. Third, stress as an interaction consists of the individual's response to a stimulus from the surroundings; not only can an individual connect a stimulus element of the surroundings with a response, but personal characteristics can also affect the surroundings. From the interactional perspective, psychological stress can be a certain relation between an individual and their environment, which is evaluated to exceed the personal resource and threatens their comfort (Lazarus and Folkman 1984).

Modern society is composed of numerous stressors. That nothing can be done without stress means that stress may be an origin of many illnesses. To sum up the study results of the medical and psychological world on stress, it is an indisputable established theory that most of the illnesses mankind develops, at least in part, are due to stress 
or that stress aggravates the situation. People look for alcohol and recreational drugs or use coffee or cigarettes to relieve stress; however, certain items of personal preference for stress relief can produce bigger stresses and destroy their health.

One non-medical method of stress reduction is laughing and being in pleasant environments. Laughter is a positive sensation, and seems to be a useful and healthy way to overcome stress. Decreasing stress-making hormones found in the blood, laughter can mitigate the effects of stress (Farifteh et al. 2014). A popular theory for understanding laughter includes its evolution as a relief of nervous energy, potentially making it an ideal antidote for stressful situations. This is supported by the empiric observation that laughter decreases serum levels of cortisol, epinephrine, growth hormone, and 3,4-dihydrophenylacetic acid (a major dopamine catabolite), indicating a reversal of the stress response (Berk et al. 1989a). In a previous study, 33 subjects viewed a humorous video and, subsequently, stress level and immune function (natural killer cell activity) were recorded. As a result, stress level decreased and immune function increased in the experimental group compared with the control group (Bennett et al. 2003).

Since 1970, laughter has been regarded as a complementary and alternative therapy (Cousins 1976). As laughter is a noninvasive complementary/alternative therapy, the use of laughter therapy has spread rapidly. Currently, there are several laughter therapy clubs around the world in which people gather to practice laughter and laughing on purpose; this fake laughter gradually becomes effective in releasing "anti-stress and joyful hormones" (Ghodsbin et al. 2014).

\section{Laughter and Depression}

The word 'melancholia' started to be used by at least B.C. 400, when Hippocrates first recorded and described it. 'Depression', typically used synonymously with 'melancholia', first began to be used when Bleuler (1911) described it, and that overall depression includes phenomena such as kinetic phenomena occurring as a result of all mental actions, such as mind, mood, and consciousness that feels depression, excitement, and satisfaction, or, more loosely, it refers to the element that occurs to the mind trying to accomplish something and is forcibly oppressed (Ko and Youn 2011).

Depression has a very high rate of prevalence and is one of the most common mental disorders. It can be defined as the depressed state of the pathological level. That is to say, depression refers to a kind of mental disease where people are seized by a sense of inadequacy, of isolation, of futility and of guilt and suicidal impulse in a depressed mood and in demotivation; it is different from a temporary depressed feeling (Shahidi et al. 2011). A depressed feeling is an emotional response of being sad, hopeless, frustrated, or dispirited, which are almost relieved when situations improve, but depression is a disease, where neurotransmitters in the brain, such as norepinephrine, dopamine, and serotonin, are reduced and there is something wrong in the mood control circuit of the brain. It is a disease that weakens both mind and body, including physical symptoms, moods, and thoughts (Cho and Oh 2011). Specifically, when people feel severely down, the symptom can be called depression. It is termed clinical depression when pent-up, inactive, and worried feelings continue at least 2 weeks, not allowing an individual to lead a normal life. Clinical depression also requires drug treatment; therefore, depression needs to be divided into the general depressed feeling and severe depression. Unlike the temporary depressed feeling, depression does not vary according to situation and can continue for years if not cured (Caspi et al. 2003).

Laughter helps people endure stressful processes or situations, reduces depression, helps people judge their problems objectively, and improves problem-solving ability by increasing insight. Therefore, laughter helps people prevents themselves from being influenced by the environment and control themselves (Wooten 1996). There is also an opinion that laughter is a pleasant stress, which means laughter is a stress that has a positive aspect and gives fresh and powerful energy. Thus, laughter is used to reduce negative cognitive responses and relieves stress (Bennett 2003; MacDonald 2004). It is reported laughter has the best effect among methods that can relieve stress, and that if we keep practicing even a forced laugh, our body will react to it and become more pleased and healthy (Ekman 1984; Lefcourt and Martin 2012). A positive mood can be gained through the forced laugh, and a bad mood, personality, or thought can be changed somewhat into a positive direction (Isen and Means 1983). According to the latest precedent studies, reduction in secretion of the neurotransmitters, dopamine and serotonin, is the representative of one of the many causes of depression; therefore, if the secretion of those substances reduces, there will be a disorder in mood control in the brain and depression will develop (Brown and Gershon 1993). However, a positive attitude and forced laughter can help maintain dopamine activity (Ashby et al. 1999). Furthermore, endorphins secreted by laughter can help when people are uncomfortable or in a depressed mood (Lebowitz 2002). Moreover, in a study on the effects of laughter therapy on depression in middle-aged women and their blood serotonin concentration, blood serotonin concentration showed the lowest result in the group with the severest depression. After laughter therapy, serotonin increased in all three groups (the group without depression, with a little depression, and with severe depression) except the control group, and the group with severe depression showed the greatest change (Cha and Hong 2015). Serotonin is a control hormone, which controls impulsivity and tension to maintain calmness and activate the limbic system, so that it becomes a source of the will to live and vitality. Therefore, it is a substance that acts in opposition to depression (Lee 2010). Due to this characteristic, sero- 
tonin is drawing people's attention in its role in healing anxiety, stress, antisocial behavior, and mental diseases. In particular, serotonin is known to be activated by continuous exercise or yoga (Kim 2006). As exercise or yoga increases the positive energy and vitality of the body and activates serotonin in the blood, so laughter has a similar influence to adequate exercise or yoga by increasing our pulse and lung capacity and helping the digestive system (Dolgoff-Kaspar et al. 2012). Therefore, as it increases blood dopamine and serotonin concentration, laughter therapy may be very effective in reducing depression as a non-pharmacological, alternative treatment.

\section{Conclusion}

Laughter therapy as a non-pharmacological, alternative treatment does not require specialized preparations such as suitable facilities and equipment, is not prohibited by cost, does not depend on when or where it happens, and is easily accessible and acceptable (Mora-Ripoll 2010; Ko and Youn 2011). For these reasons, the medical world has taken notice and attempted to include it to more traditional therapies. Laughter therapy gives our body various physiological changes, and has an influence on the physical temperature, blood pressure, lung capacity, heart rate, muscles in the musculoskeletal system, and brain activity, so it can have an overall effect in promoting health (Hayashi et al. 2007; Bennett and Lengacher 2009). Mentally, laughter therapy helps reduce unpleasant feelings such as tension, anxiety, hatred, and anger, alleviates feelings of depression, aids better interpersonal relationships, and improves insomnia, memory failure, and dementia (Takeda et al. 2010; Bains et al. 2015). As modern society has an issue with the effect that fierce competition and socioeconomic problems have on quality of life and that stress and depression from these problems can have a negative influence on a person's mental health, the promotion of mental health through laughter therapy can be a very effective and meaningful approach (Bast and Berry 2014). Laughter therapy for stress and depression, representative cases that have a negative influence on mental health, is a noninvasive and nonpharmacological alternative treatment. Laughter is a positive sensation, and seems to be a useful and healthy way to overcome stress. Decreasing stress-making hormones found in the blood, laughter can mitigate the effects of stress (Farifteh et al. 2014). There is also an opinion that laughter is a pleasant stress, which means laughter is a stress that has a positive aspect and gives fresh and powerful energy. Thus, laughter is used to reduce negative cognitive responses and relieves stress (Bennett 2003; MacDonald 2004). Therefore, it is effective and scientifically supported as either a single or adjuvant therapy. At the same time, it can also provide a comprehensive approach that can improve the quality of life and social relationships.

\section{Acknowledgments}

This study was supported by Sahmyook University.

\section{Conflict of Interest}

The author declares no conflict of interest.

\section{References}

Apte, M.L. (1985) Humor and laughter: An Anthropological Approach, Cornell Univercity Press, Ithaca, NY.

Arminen, I. \& Halonen, M. (2007) Laughing with and at Patients: the Roles of Laughter in Confrontations in Addiction Group Therapy. The Qualitative Report, 12, 484-513.

Ashby, F.G., Isen, A.M. \& Turken, A.U. (1999) A neuropsychological theory of positive affect and its influence on cognition. Psychol. Rev., 106, 529-550.

Bains, G.S., Berk, L.S., Lohman, E., Daher, N., Petrofsky, J., Schwab, E. \& Deshpande, P. (2015) Humors effect on shortterm memory in healthy and diabetic older adults. Altern. Ther. Health Med., 21, 16-25.

Bast, E.S. \& Berry, E.M. (2014) Laugh away the fat? Therapeutic humor in the control of stress-induced emotional eating. Rambam Maimonides Med. J., 5, e0007.

Bennett, H.J. (2003) Humor in medicine. South. Med. J., 96, 1257-1261.

Bennett, M.P. \& Lengacher, C. (2006) Humor and laughter may influence health: II. complementary therapies and humor in a clinical population. Evid. Based Complement. Alternat. Med., 3, 187-190.

Bennett, M.P. \& Lengacher, C. (2008) Humor and laughter may influence health: III. laughter and health outcomes. Evid. Based Complement. Alternat. Med., 5, 37-40.

Bennett, M.P. \& Lengacher, C. (2009) Humor and laughter may influence health IV. humor and immune function. Evid. Based Complement. Alternat. Med., 6, 159-164.

Bennett, M.P., Zeller, J.M., Rosenberg, L. \& McCann, J. (2003) The effect of mirthful laughter on stress and natural killer cell activity. Altern. Ther. Health Med., 9, 38-45.

Berk, L. \& Tan, S. (1995) Eustress of mirthful laughter modulates the immune system lymphokine interferon-gamma. Proceedings of the Society of Behavioral Medicine's 16th Annual Scientific Sessions. Ann. Behav. Med. Suppl., 17, C064.

Berk, L.S., Tan, S.A., Fry, W.F., Napier, B.J., Lee, J.W., Hubbard, R.W., Lewis, J.E. \& Eby, W.C. (1989a) Neuroendocrine and stress hormone changes during mirthful laughter. Am. J. Med. Sci., 298, 390-396.

Berk, L.S., Tan, S.A., Napier, B.J. \& Eby, W.C. (1989b) Eustress of mirthful laughter modifies natural killer cell activity. Clin. Res., 37, 115A.

Bleuler, E. (1911) Dementia Praecox Oder Gruppe der Schizophrenien, Deuticke, Leipzig, Germany.

Brown, A.S. \& Gershon, S. (1993) Dopamine and depression. J. Neural Transm. Gen. Sect., 91, 75-109.

Caspi, A., Sugden, K., Moffitt, T.E., Taylor, A., Craig, I.W., Harrington, H., McClay, J., Mill, J., Martin, J., Braithwaite, A. \& Poulton, R. (2003) Influence of life stress on depression: moderation by a polymorphism in the 5-HTT gene. Science, 301, 386-389.

Cha, M.Y. \& Hong, H.S. (2015) Effect and path analysis of laughter therapy on serotonin, depression and quality of life in middle-aged women. J. Korean Acad. Nurs., 45, 221-230.

Cho, E.A. \& Oh, H.E. (2011) Effects of laughter therapy on depression, quality of life, resilience and immune responses in breast cancer survivors. J. Korean Acad. Nurs., 41, 285-293.

Cousins, N. (1976) Anatomy of an illness (as perceived by the patient). N. Engl. J. Med., 295, 1458-1463.

Cousins, N. (1989) “The Laughter Connection", Head First: The 
Biology of Hope and the Healing Power of the Human Spirit, Penguin Books, New York, NY.

Dean, R.A.K. \& Gregory, D.M. (2004) Humor and laughter in palliative care: an ethnographic investigation. Palliat. Support. Care, 2, 139-148.

Dolgoff-Kaspar, R., Baldwin, A., Johnson, M.S., Edling, N. \& Sethi, G.K. (2012) Effect of laughter yoga on mood and heart rate variability in patients awaiting organ transplantation: a pilot study. Altern. Ther. Health Med., 18, 61-66.

Ekman, P. (1984) Expression and the nature of emotion. Approaches to Emotion, 3, 19-344.

Ekman, P., Davidson, R.J. \& Friesen, W.V. (1990) The Duchenne smile: emotional expression and brain physiology: II. J. Pers. Soc. Psychol., 58, 342-353.

Evans, R.G. (1982) Skill versus chance tasks comparison of locus of control, Ddfensive externality, and persistence. Pers. Soc. Psychol. Bull., 8, 129-133.

Farifteh, S., Mohammadi-Aria, A., Kiamanesh, A. \& Mofid, B. (2014) The impact of laughter yoga on the stress of cancer patients before chemotherapy. Iran. J. Cancer Prev., 7, 179-183.

Freud, S. (1928) On humor. The Psychoanalytic Review (19131957), 15, 85.

Fry, W.F. \& Salameh, W.A. (1987) Handbook of Humor and Psychotherapy: Advances in the Clinical Use of Humor, Professional Resource Exchange, Inc, Sarasota, FL.

García-Rodera, M. (2007) Cómo beneficiarse del poder de la risa, edited by Morales I, Torres, Madrid, Barcelona.

Gelkopf, M., Gonen, B., Kurs, R., Melamed, Y. \& Bleich, A. (2006) The effect of humorous movies on inpatients with chronic schizophrenia. J. Nerv. Ment. Dis., 194, 880-883.

Ghodsbin, F., Ahmadi, Z.S., Jahanbin, I. \& Sharif, F. (2014) The effects of laughter therapy on general health of elderly people referring to jahandidegan community center in Shiraz, Iran, 2014: a randomized controlled trial. Int. J. Community Based Nurs. Midwifery, 3, 31-38.

Hasan, H. \& Hasan, T.F. (2009) Laugh yourself into a healthier person: a cross cultural analysis of the effects of varying levels of laughter on health. Int. J. Med. Sci., 6, 200-211.

Hayashi, T., Tsujii, S., Iburi, T., Tamanaha, T., Yamagami, K., Ishibashi, R., Hori, M., Sakamoto, S., Ishii, H. \& Murakami, K. (2007) Laughter up-regulates the genes related to NK cell activity in diabetes. Biomed. Res., 28, 281-285.

Hyeong Woo, P. (2010) The effect of laughter therapy program on mental health. Korean J. Str. Res., 18, 287-294.

Isen, A.M. \& Means, B. (1983) The influence of positive affect on decision-making strategy. Soc. Cogn., 2, 18-31.

Ivancevich, J.M. \& Matteson, M.T. (1980) Stress and Work: A Managerial Perspective, Scott, Foresman Dallas.

Keith-Spiegel, P. (1972) Early Conceptions of Humor: Varieties and Issues, Academic Press, New Uork, NY.

Kim, H. (2006) Effects of 20 weeks yoga on neurotransmitter in educable mentally retarded teenagers [master's thesis], Sookmyung Women's University, Seoul.

Ko, H.J. \& Youn, C.H. (2011) Effects of laughter therapy on depression, cognition and sleep among the communitydwelling elderly. Geriatr. Gerontol. Int., 11, 267-274.
Lazarus, R.S. \& Folkman, S. (1984) Coping and Adaptation. The handbook of Behavioral Medicine, edited by Gentry, W.D. Guilford, New York, p. 282-325.

Lebowitz, K.R. (2002) The effects of Humor on Cardiopulmonary Functioning, Psychological Well-Being, and Health Status among Older Adults with Chronic Obstructive Pulmonary Disease, The Ohio State University, Columbus, $\mathrm{OH}$.

Lee, S. (2010) Serotonin Here \& Now, Joongang Books, Seoul, Korea.

Lefcourt, H.M. \& Martin, R.A. (2012) Humor and Life Stress: Antidote to Adversity, Springer Science \& Business Media, New York, NY.

MacDonald, L.C.M. (2004) A chuckle a day keeps the doctor away: therapeutic humor \& laughter. J. Psychosoc. Nurs. Ment. Health Serv., 42, 18-25.

MacGhee, P.E. \& Pistolesi, E. (1979) Humor: Its origin and development, W.H. Freeman and Company, San Francisco, CA.

Martin, R.A. (2010) The Psychology of Humor: An Integrative Approach, Academic Press, Cambridge, Massachusetts.

Martin, R.A. \& Lefcourt, H.M. (2004) Sense of humor and physical health: theoretical issues, recent findings, and future directions. Humor, 17, 1-20.

Mora-Ripoll, R. (2010) The therapeutic value of laughter in medicine. Altern. Ther. Health Med., 16, 56-64.

Omwake, L. (1937) A study of sense of humor: its relation to sex, age, and personal characteristics. J. Appl. Psychol., 21, 688-704.

Provine, R. (2000) The science of laughter. Psychol. Today, 33, 58-63.

Ripoll, R.M. \& Rodera, M.C.G. (2008) Therapeutical value of laughter in medicine. Med. Clin. (Barc.), 131, 694-698.

Sahakian, A. \& Frishman, W.H. (2007) Humor and the cardiovascular system. Altern. Ther. Health Med., 13, 56-58.

Scholl, J.C. \& Ragan, S.L. (2003) The use of humor in promoting positive provider-patient interactions in a hospital rehabilitation unit. Health Commun., 15, 319-330.

Schultz, T.R. \& Horibe, F. (1974) Development of the appreciation of verbal jokes. Dev. Psychol., 10, 13-20.

Shahidi, M., Mojtahed, A., Modabbernia, A., Mojtahed, M., Shafiabady, A., Delavar, A. \& Honari, H. (2011) Laughter yoga versus group exercise program in elderly depressed women: a randomized controlled trial. Int. J. Geriatr. Psychiatry, 26, 322-327.

Sonnentag, S. \& Frese, M. (2003) Stress in Organizations, Wiley Online Library.

Stearns, F.R. (1972) Laughing: Physiology, Pathophysiology, Psychology, Pathopsychology, and Development, Charles C Thomas Pub. Ltd., Springfield, IL.

Takeda, M., Hashimoto, R., Kudo, T., Okochi, M., Tagami, S., Morihara, T., Sadick, G. \& Tanaka, T. (2010) Laughter and humor as complementary and alternative medicines for dementia patients. BMC Complement. Altern. Med., 10, 1-7.

Wooten, P. (1996) Humor: an antidote for stress. Holist. Nurs. Pract., 10, 49-56.

Wortzel, H.S., Oster, T.J., Anderson, C.A. \& Arciniegas, D.B. (2008) Pathological laughing and crying. CNS Drugs, 22, 531-545. 